\title{
A Structural Analysis of the Cardington British Steel Corner Test.
}

\author{
M. Gillie†, A.S Usmani and J.M. Rotter. \\ School of Civil and Environmental Engineering, \\ University of Edinburgh, Edinburgh, EH9 3JN, United Kingdom, +44 (0)131 6505813 \\ †Corresponding author
}

\begin{abstract}
This paper presents a structural analysis of the Cardington British Steel Corner Test. The test is analysed using ABAQUS, the commercial finite element program. The results of the analysis indicate that the response of the structure is dominated by the effects of thermal expansion and that material degradation and gravity loading are of secondary importance until very late in the test. It is noted however that at extreme temperatures a significant load carrying mechanism is tensile action in the reinforcement mesh and that gravity loading can effect the magnitude of the tensile forces produced. The results suggest that one method of helping maintain structural integrity in composite structures during extreme fires is to ensure that a sufficient amount of ductile reinforcement is present in the concrete floor slabs.
\end{abstract}

Keywords: Cardington, Fire, Finite element, Structural analysis, FEAST

\section{Introduction}

The behaviour of composite steel-framed structures in fire conditions, such as the office buildings found in many modern cities, is extremely complex. In recent years it has been accepted that the traditional methods of fire safety engineering have been developed from an inadequate understanding of the behaviour of heated structures. This has led to the application of expensive fire protection that may have been unnecessary in many instances. To allow the behaviour of composite structures in fire conditions to be studied, a series of tests were performed on a full scale, eight storey, steel-framed 
building in 1995 at Cardington, UK. ${ }^{1-3}$ These experiments produced a huge amount of experimental data and it was intended that this data be used to develop a detailed understanding of the physical phenomena which dominate structural behaviour under fire loading. This paper is concerned with gaining some of this understanding. The Cardington tests, together with recent advances in computing power and modelling techniques, have allowed a new generation of numerical models of heated structures to be developed. Previous research into modelling isolated structural elements and simple frames has shown that it is difficult to obtain accurate models, even when experimental data is available for verification. Clearly, attempting to model 3-dimensional structures with no experimental data would not have produced reliable predictions. The availability of the Cardington experimental data prompted a number of groups to attempt to model the fire tests and to obtain an understanding of the structural behaviour based on the results of their models.

Workers at Sheffield University have produced numerical models of the fire tests ${ }^{4-7}$ conducted at Cardington using the VULCAN ${ }^{6}$ finite element program, previously known as INSTAF. ${ }^{5}$ The work described by the Sheffield group is valuable but also incomplete in a number of ways. One criticism is that the model of the concrete floor slab used in much of the work did not allow for changes in the geometry of the structure. The consequence of this is that $\mathrm{P}-\Delta$ effects could not have been accounted for in the slab analysis. To some extent this drawback has been addressed in more recent work by the group. ${ }^{8}$ Analysts at Imperial College, London have used the $\mathrm{ADAPTIC}^{9}$ finite element package to model the Cardington tests. ADAPTIC only includes beam elements and so the analyses have been performed by descretizing the Cardington tests in the form of a grillage. The results were reported in 2000 by Elgazhouli. ${ }^{10}$ This model included non-linear material behaviour, non-linear geometry and a full range of thermal effects. Researchers at British Steel (now Corus PLC) have developed a number of numerical models to investigate aspects of the Cardington tests. ${ }^{11-13}$ Models of the floor slab using linear elastic shell elements with discrete hinges where yield lines were expected to develop were produced for the restrained beam test, the British steel corner test and the office demonstration test. The orthotropic nature of the slab was modelled by including beam elements attached to the shell elements in one direction. Although including hinges along predetermined lines is clearly an a priori 
assumption, these models were able to provide useful insights into which aspects of the Cardington frame were dominant in governing its behaviour. The research group at Edinburgh University has used the commercial finite element package, ABAQUS, ${ }^{14}$ to model the Cardington tests. ${ }^{12,13,15-17}$ Some of their models used beam elements with fully non-linear material behaviour to represent the steel frame and a grillage of beam elements defined using a stress-resultant approach to model the floor slab. This approach had the disadvantage of not allowing any interaction between bending and axial forces to be modelled. The constitutive behaviour of the grillage beams was determined by a simple trilinear model.

This brief overview of previous work in the area shows that to date all numerical work on analysing the Cardington structure has been lacking in one or more areas. Work using shell elements to represent concrete floors has tended to either use very simple material behaviour and include various ad hoc assumptions, or has not included numerical representation of key phenomena such as geometric nonlinearity. Work that has not been deficient in these respects has resorted to using a grillage of beam elements to represent a continuous floor slab. While all these models have been useful in gaining new insights into the behaviour of structures in fire conditions, it is clearly necessary for a more rigorous numerical model to be developed before any firm conclusions can be drawn. The need for such a model is made more important by the move towards performance based fire safety design codes. In addition, most previous work has concentrated on modelling the tests and obtaining accurate matches with experimental data. This is clearly necessary but a clear understanding of the key structural phenomena is also required. Unless engineers have a good understanding of how heated structures behave, they will not be able to take full advantage of modern performance based design codes.

This paper presents a structural analysis of the third Cardington test using results from the FEAST program. FEAST is a user-defined subroutine that can be used with ABAQUS to specify the behaviour of shell elements using a stress-resultant approach. The use of FEAST means that the analysis accounts for full material and geometric non-linearity as well as thermal expansion, thermal curvature and non-linear thermal gradients. The orthotropic nature of the slab was also accounted for in the analysis. Full details of FEAST have been given elsewhere. ${ }^{18,19}$ This paper presents information on 
the forces that developed in the structure and attempts to disentangle the complex response seen. It is complimentary to previous work by Gillie $e t a l^{20}$ that described an analysis of the first Cardington test using FEAST. Whilst this previous work had similar aims to the present paper, the relative simplicity of the first Cardington test meant the the conclusions that could be drawn were rather limited in nature.

\section{The Finite Element Model}

The location of test three within a typical floor of the Cardington frame is shown in Fig. 1. The heated compartment included several secondary beams, a primary beam and the associated areas of floor slab. The columns were protected, as were the internal faces of the edge beams. Temperature loading was supplied by burning wooden cribs. As two sides of the test compartment were along edges of the structure, there was relatively little in-plane restraint in these regions.

In order to increase the speed of calculation, it was decided to limit the area of the the Cardington frame modelled to that in the vicinity of the test. Previous work has shown that it is acceptable to represent the effect of a continuous floor slabs with symmetry boundary conditions ${ }^{20-22}$ and this approach was used at the internal boundaries of the model. A schematic diagram of area of the structure modelled is shown in Fig. 2. The figure also shows the grid system used for referring to the various beams and columns. For example, the column at the corner of the test compartment is column F1.

As mentioned, at the internal edges of the mesh symmetry boundary conditions were assumed. The external boundaries were left free. The columns were modelled from one floor below the tested compartment to one floor above it. Only vertical deflections were allowed at the top of the columns and the bottom ends were fixed. The floor slab was modelled using eight-noded reduced integration shell elements and the columns and beams using two noded beam elements. A diagram of the mesh is shown in Fig. 3.

The floor slab was subject to a uniformly distributed gravity load of $5.81 \mathrm{kN} / \mathrm{m}^{2}$ which resulted from 
its self-weight and from sand bags placed on it to simulate live loads. ${ }^{1}$ In the nunerical model this load was applied as a uniformly distributed load over the entire floor slab. Along the edges of the fire compartment there was an additional gravity load that resulted from the weight of the compartment walls. The weight of these walls was not recorded but was estimated as $19.2 \mathrm{kN} / \mathrm{m}$ from the fact that they were constructed from hollow concrete blocks. The columns were loaded axially to account for the weight of the structure they were supporting.

The temperature loading was complex because the temperature peaked in different parts of the structure at different times. Fig. 4 shows how the temperatures in various beams varied with time during the test. The unprotected beams all reached their peak temperatures at approximately the same time but the temperature of the protected edge beams was still rising at this point. The temperature of the slab at various sections through its depth at a typical location is shown in Fig. 5. The temperature peaked in the lower sections of the slab at around the same time as in the unprotected beams, however the peak temperature of the upper sections was not reached until later in the test. Modelling of the structure during cooling was seen as a separate problem and beyond the scope of this paper so it was decided to restrict the analysis to the part of the test in which all parts of the fire compartment were getting hotter. This meant modelling the first eighty minutes of the test.

\section{Comparisons with Test Data}

A mathematical surface was fitted to the experimental deflection data after eighty minutes and this is plotted as a contour diagram in Fig. 6. The numerical data is plotted in a similar manner in Fig. 7 and it can be seen that the two diagrams correlate closely. A comparison of predicted and experimental deflections through time is shown in Fig. 8. The predicted deflections with a linear temperature-time variation in the slab are also shown. It is clear that although the match between the two is good along beam $12 \mathrm{E}$, that along EF1/2 is relatively poor until late in the test. There are a number of reasons for the discrepancies between the numerical and experimental results.

A good estimate of the vertical and horizontal variation of temperatures within the floor slabs is cru- 
cial to producing accurate numerical models. By contrast, a detailed knowledge of the temperature distribution within the steel beams is less important. The Cardington experiments were designed before the relative importance of these temperatures was appreciated. Indeed the designers seem to have felt that the situation was reversed because the steel beams in the Cardington frame were probably over-instrumented while there is a lack of knowledge about slab temperatures. The complexity of the test and the limited slab temperature data meant that it was not possible to accurately assess the three dimensional temperature regime in the slab through time and a number of approximations had to be made. Such approximations inevitably limited the accuracy of the predicted deflections. The strong effect that the slab temperatures had on deflections can be seen in Fig. 8 by comparing the predicted deflections for linear and non-linear slab temperature regimes.

\section{The Structural Behaviour}

The development of axial force in two of the beams within the structure is shown in Figs. 9 and 10. The forces in the internal secondary beam (Fig. 9) were strongly governed by the restraint to axial expansion provided by the cool and therefore stiff concrete floor slab surrounding the test compartment on two sides. As the temperature of the beam rose, the axial forces within it initially developed linearly until, at around $130^{\circ} \mathrm{C}$, the beam yielded. Beyond this point the forces remained about constant until declining material properties caused them to reduce from around $450^{\circ} \mathrm{C}$. This reduction in axial force was hastened by the large deflection developing towards the end of the test that would have allowed some of the thermal strains to have been dissipated through geometric lengthening of the beam. It is noticeable that towards the external end of the beam the forces developed were only around half those at mid-span. This is to be expected because the end of the beam was subject to lower axial restraint. However, the fact that $50 \%$ of the mid-span force was still present indicates that significant axial restraint was provided by the edge of the structure.

The behaviour of the external primary beam $12 \mathrm{~F}$, Fig. 10, was different to the secondary beam as the it was fire protected and therefore heated more slowly and to a lower temperature. The temperature 
regime was similar to the heated slab (Fig. 5), although it should be noted that the slab's coefficient of thermal expansion was less than that of the steel $\left(9.5 \times 10^{-6}{ }^{\circ} \mathrm{C}^{-1}\right.$ opposed to $\left.12.3 \times 10^{-6}{ }^{\circ} \mathrm{C}^{-1}\right)$. This arrangement meant that the thermal strain in beam $12 \mathrm{~F}$ could, to a significant extent, be accommodated by the expansion of the slab and consequent horizontal translation of column F1. As a result the beam yielded much later in the test than the internal beams and provided a degree of in-plane restraint on the external edge of the structure.

Along line $1 / 2$ in the thin direction of the slab the pattern of forces above ambient temperature was largely dominated by two effects (Fig. 11). Initially, membrane tension was produced in the slab as a result of deflections, which at this stage were driven by the expanding steel joists (see below). At higher temperatures the slab had expanded sufficiently for compression to be produced due to restrained thermal expansion at the internal side. At around $6000 \mathrm{~mm}$ from the edge of the structure the effects of large deflections and thermal expansion almost balanced each other and so produced tensions that rose, fell and then rose again as the test progressed. Along line 2, Fig. 12, the restraint to thermal expansion was higher due to the proximity of the fire compartment boundary. This resulted in compressive forces being setup up in the slab from the start of the heating and increasing steadily throughout the test.

The pattern of forces in the slab in the directions of the ribs is shown in Figs. 13 and 14. The behaviour on line E/F (Fig. 13) was tensile throughout the test and resulted from the large deflections at midspan (which were being driven by the slab expanding parallel to line $1 / 2$ ) requiring a greater increase in slab length than was available from the rib thermal expansion. Along line E (Fig. 14) the membrane forces were increasingly compressive throughout the test because deflections were quite low in this region.

Fig. 15 shows the effect various changes in the numerical model on the deflections at mid-span in beam $\mathrm{EF} 1 / 2$.

In the initial stages of the test, the temperature of the steel beams rose much more rapidly than that of the concrete slab. Consequently, the thermal expansion of the steel was restrained and a large 
eccentric thrust was produced over the composite section which in turn led to deflections. Specifying zero thermal expansion in the numerical model for the beams had the effect of removing the initial composite thermal gradient. Fig. 15 shows this resulted in low deflections until $400^{\circ} \mathrm{C}$, after which deflections increased rapidly as the structure adopted a post-buckled state. Towards the end of the test, when the strength of most of the steel was minimal, the effect of zero steel thermal expansion on deflections was small.

There were a number of possible causes for the vertical deflections after the steel beams had yielded:

- Lateral restraint to thermal expansion

- Thermal curvature of the slab

- Loss of strength and increasing stiffness in the slab due to material degradation

Fig. 15 suggests that the strongest mechanism for producing deflections after $400^{\circ} \mathrm{C}$ was restrained thermal expansion of the slab. When the coefficient of the thermal expansion for the slab was assumed to be zero (and therefore the slab thermal gradient equal to zero), the increase in deflection beyond $400^{\circ} \mathrm{C}$ was small. When a uniform slab temperature was assumed, significantly increased deflections were produced beyond $780^{\circ} \mathrm{C}$. This rapid increase coincided with the point at which the temperature of the slab started in increase more quickly (Fig. 5). For membrane thermal expansion to produce these deflections, lateral restraint to the expansion would have been needed. The only significant mechanisms available for providing this restraint came from slab because the columns would have had very little resistance to lateral forces.

The surrounding structure was able to provide a significant amount of restraint to thermal expansion because of the in-plane behaviour of the slab. Due to compatibility requirements, the cold floor slab surrounding the heated compartment prevented the hot area of slab expanding fully. This effect was strongest near the internal boundaries of the heated compartment where the very stiff, cold portion of floor slab provided a significant amount of restraint. However, a degree of restraint was also provided by the cooler strips of slab along the external boundaries of the structure acting compositely with the protected edge beams. 
Fig. 15 suggests that the role of the thermal gradient in the slab was of secondary importance in producing deflections. The addition of a thermal gradient to the calculation for uniform heating smoothed the overall response and increased the magnitudes of the deflections slightly. It did not, however, change the fundamental deflection pattern.

It is clear from Fig 15 that the effect of doubling the gravity load was to increase deflections. As expected, the initial deflections were doubled by increasing the load but later in the test the difference in deflection between the two cases were much less than $50 \%$, emphasising the non-linearity of the problem. However, as the test progressed, the differences between the two load cases increased in absolute terms, suggesting that the behaviour of the structure was increasingly affected by its bending behaviour at higher temperatures.

The mechanical strains in the reinforcement mesh at the end of the test are shown in Figs. 16 and 17. In the $y$ (rib) direction there was a clear area of tension (positive strains) near the centre of the heated region. Here the slab deflections were driven by compatibility requirements. Although there was a significant tensile slab membrane force in this region (Fig. 13), the reinforcement strains remained relatively low due the thermal expansion of the steel. It is noticeable that in the region of slab just outside the heated compartment, much higher tensile strains were produced. These strains were again due to compatibility requirements but in this region it was compatibility of strains between the hot and cold slab that governed the behaviour. The mechanical strains in this region were greater than the yield strain of the steel. The strain behaviour in the $x$ (thin) direction was simpler. The mesh was in compression in the entire heated region at the end of test, despite small areas of tension in the slab. The compressive strains were produced by the large thermal strains that were developed in the steel due its location near the bottom of the slab. As in the $y$-direction, there was a region of high tensile strain adjacent to the heated compartment which resulted from the requirement of compatibility of total strains in the slab. 


\section{Conclusions}

The results presented in this paper together with the analysis of the first Cardington test ${ }^{20}$ show that the behaviour of heated structures is considerably more complex than the behaviour of structures at ambient temperature. A number of important phenomena that occur in composite structures only at high temperatures have been identified and these are summarised below:

- The results show that the effects of restrained thermal expansion are dominant in governing the behaviour of heated composite structures. Restraint to thermal expansion can come either from within a fire compartment or from outside it. In the early stages of a fire, internal restraint is provided by the concrete slab. Due to their high thermal diffusivities, the temperatures of the steel beams rise much more rapidly than those of concrete slabs. The consequence of this differential heating is that the hot steel beams are restrained from expanding by the cooler concrete slab and large curvatures and therefore deflections are produced. This mechanism is self-limiting because the restraint that causes the deflections also causes the steel beams to yield in axial compression. The decline of steel material properties at high temperatures means that in the later stages of fires this deflection mechanism is active in fire protected beams.

- Restraint from outside a heated compartment relies on the compartment having at least two boundaries with unheated, laterally stiff parts of the structure. If such restraint exists on opposite sides of a fire compartment then it has been $\operatorname{shown}^{20,23}$ that the concrete slab reaches a post-buckled state and large deflections result. If restraint is present on two sides of a fire compartment that are perpendicular to each other, this can still produce membrane compressions in the slab due to in-plane shear behaviour.

- The role of thermal gradients through the depth of floor slabs was found to be more important at higher temperatures after the steel beams had lost much of their strength. Thermal gradients produced hogging moments in the slab which gave rise to increasing deflections. These thermally induced hogging moments may be present in geometrically sagging regions. 
- In rectangular fire compartments, the available thermal extension in the floor slab parallel to the longer side is greater than that parallel to the shorter side. At any point in the floor slab, deflections must be compatible between the two directions. These two facts mean that tensions can be produced in the floor slab parallel to the shorter side of a fire compartment due to the deflections being driven by the thermal extension of the longer side.

- Tensile membrane action has been found to be an important load carrying mechanism at large deflections in heated structures. Heating of the reinforcement bars means that the mechanical strains may remain low, even at high deflections, thus reducing the chances of rupture. In the light of this, it would seem sensible for designers to include more than the minimum amount of reinforcement necessary to prevent cracking in floor slabs at ambient temperatures so that structural integrity in extreme fires can be assured. Ensuring that the reinforcement used is highly ductile so that it can cope with large strains would also seem prudent. This could be done by specifying mild steel rather than high tensile steel for the mesh.

- The requirement of compatible total strains between heated and unheated regions of a structure means that large tensile strains can be produced outside the boundaries of a heated region. 


\section{References}

[1] Bravery P.N.R. Cardington large building test facility. Technical report, Building Research Establishment, 1993.

[2] Martin D.M., Kirby B.R., and O'Connor M.A. Behaviour of a multistorey, steel-framed building subjected to natural fire effects, final report. Technical report, British Steel, 1998. Confidential report.

[3] Kirby B.R. The behaviour of a multi-storey steel-framed building subjected to fire attack, experimental data. Technical report, British Steel, 1998.

[4] Bailey C.G., Burgess I.W., and Plank R.J. Computer simulation of a full-scale structural fire test. The Structural Engineer, 74(6):93-100, March 1996.

[5] Rose P.S., Burgess I.W., Plank R.J., and Bailey C.G. The influence of floor slabs on the structural behaviour of composite frames. In Lee, editor, Structures in the New Millennium, 1997.

[6] Huang Z., Burgess I.W., and Plank R.J. Nonlinear analysis of reinforced concrete slabs subjected to fire. ACI Structural Journal, 96:127-135, Jan-Feb 1999.

[7] Huang Z., Burgess I.W., and Plank R.J. Three-dimensional modelling of two full-scale fire test on a composite building. Proceedings of the Institute of Civil Engineers, Structures and Buildings, 134(1):243-255, 1999.

[8] Huang Z., Burgess I.W., and Plank R.J. Non-linear modelling of three full-scale structural fire tests. In J-M. Franssen, editor, Structures in Fire - Proceedings of the First International Workshop, pages 53-70, 2000.

[9] Izzuddin B.A and Elnashai A.S. ADAPTIC: A Program for Adaptive Dynamic Analysis of Space Frames, User Manual. Imperial College, London, 1989.

[10] Elgazhouli A.Y., Izzuddin B.A., and Richardson A.J. Numerical modelling of the structural fire response of a steel-framed building, CESLIC report CC15, PIT project report 
MD15/AM7. Technical report, Imperial College, London University, 2000. Available at www.civ.ed.ac.uk/research/fire/project/reports.html.

[11] O'Connor M. PIT project research report MD7: BS/Test2 ABAQUS model using shell elements for the beam and beam general section for the slab. Technical report, British Steel, 2000. Available at www.civ.ed.ac.uk/research/fire/project/reports.html.

[12] Sanad A.M. BS/Test3 reference ABAQUS model using beam general section. Technical report, University of Edinburgh, 2000. Available at www.civ.ed.ac.uk/research/fire/project/reports.html.

[13] Sanad A.M., Rotter J.M., Usmani A.S., and O'Connor M.A. Finite element modelling of fire tests on the Cardington composite building. In Proceedings Interflam'99, volume 2, 1999.

[14] Hibbet, Karlson and Sorenson, Providence, Rhode Island, USA. ABAQUS Users' Manual, Vols I to III, Ver 5.8, 1998.

[15] Sanad A.M. BS/Test1 reference ABAQUS model using beam general section. Technical report, University of Edinburgh, 2000. Available at www.civ.ed.ac.uk/research/fire/project/reports.html.

[16] Sanad A.M. PIT project research report AM1: Analysis of results from BS/TEST1 models, part A grillage models. Technical report, University of Edinburgh, 2000. Available at www.civ.ed.ac.uk/research/fire/project/reports.html.

[17] Sanad A.M. PIT project research report AM6: Analysis of results from BS/TEST3 models, part A grillage models. Technical report, University of Edinburgh, 2000. Available at www.civ.ed.ac.uk/research/fire/project/reports.html.

[18] Gillie M. Modelling heated composite floorslabs with ABAQUS using a UGENS subroutine. In ABAQUS Users' Conference 2000. Hibbett, Karlsson and Sorenson, INC, 2000.

[19] Gillie M., Usmani A.S., and Rotter J.M. Modelling of heated composite floor slabs with reference to the Cardington experiments. Fire Safety Journal, 36(8):745-767, 2001. 
[20] Gillie M., Usmani A.S., and Rotter J.M. A structural analysis of the first Cardington test. Journal of Constructional Steel Research, 56(6):581-601, 2001.

[21] Sanad A.M., Lamont S., Usmani A.S., and Rotter J.M. Structural behaviour in fire compartment under different loading regimes - part 1 (slab thermal gradients). Fire Safety Journal, 35:99-116, 2000.

[22] Sanad A.M., Lamont S., Usmani A.S., and Rotter J.M. Structural behaviour in fire compartment under different loading regimes - part 2 (mean slab temperatures). Fire Safety Journal, 35:117$130,2000$.

[23] Rotter J.M., Sanad A.M., Usmani A.S., and Gillie M. Structural performance of redundant structures under local fires. In Proceedings of Interflam '99, volume 2, Scotland, 1999. 


\section{Captions to Figures}

Figure 1: The layout of a typical floor of the Cardington frame.

Figure 2: Schematic plan view of the portion of the Cardington structure modelled for the analysis of test 3 .

Figure 3: The mesh used for modelling the test.

Figure 4: Variation of temperature with time in the beams.

Figure 5: Variation of temperature with time in the slab, taken from a sensor placed near the mid-span of beam EF12.

Figure 6: Contour plot of numerically predicted deflections.

Figure 7: Contours fitted to experimental deflections (experimental recorded values $(\mathrm{mm})$ are indicated).

Figure 8: Comparison of experimental and numerical deflections through time at two locations.

Figure 9: Axial force against temperature at various locations in beam EF1/2.

Figure 10: Axial force against temperature at various locations in beam 12F.

Figure 11: Membrane force in the thin direction of the slab along line 1/2.

Figure 12: Membrane force in the thin direction of the slab along line 2.

Figure 13: Rib direction membrane force along line E/F.

Figure 14: Rib direction membrane force along line E.

Figure 15: Comparison of deflections at mid-span of beam EF1/2 using various assumptions.

Figure 16: Reinforcement Mechanical Strains in the $x$-direction at the end of test 3.

Figure 17: Reinforcement Mechanical Strains in the $y$-direction at the end of test 3. 


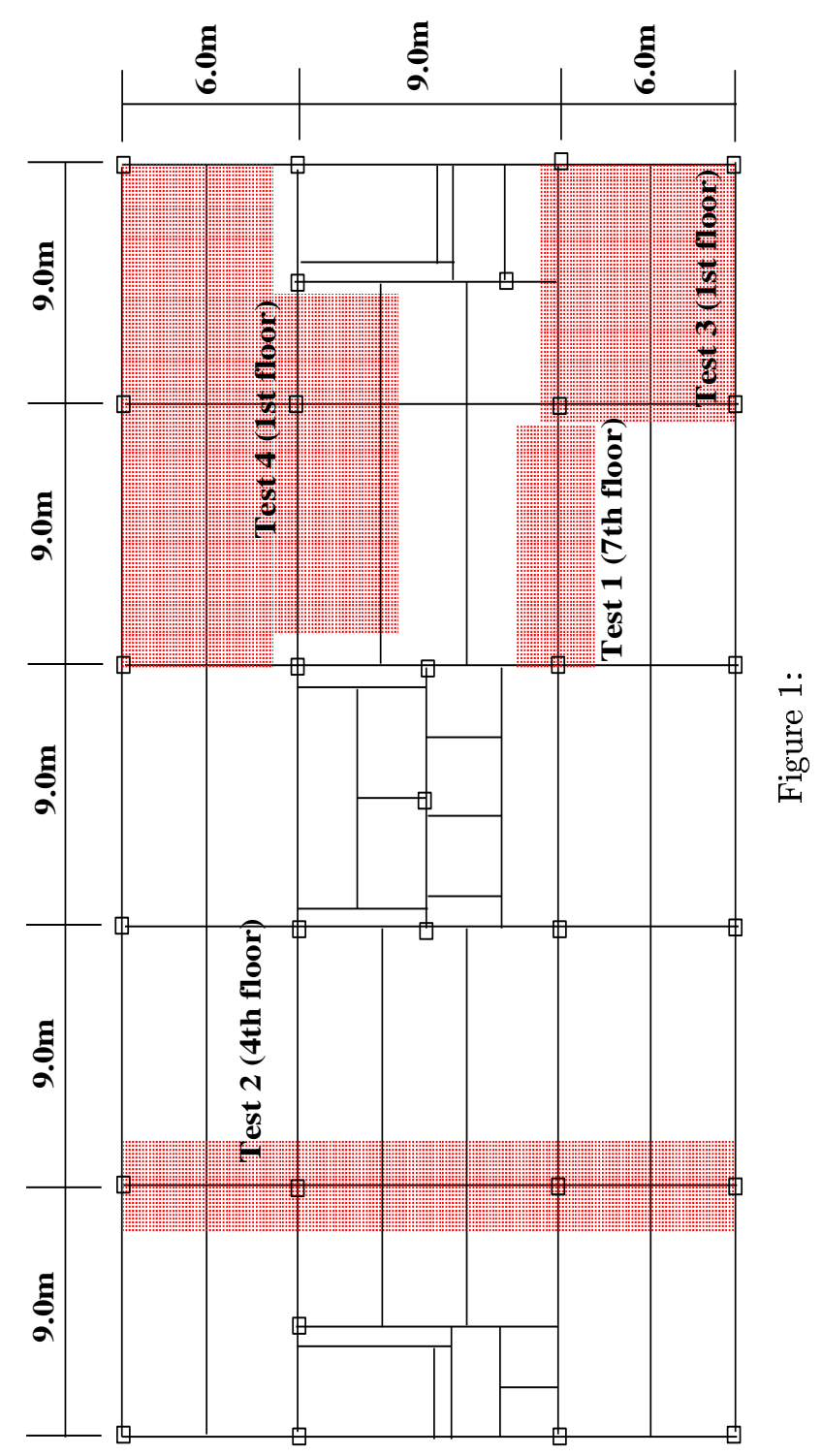




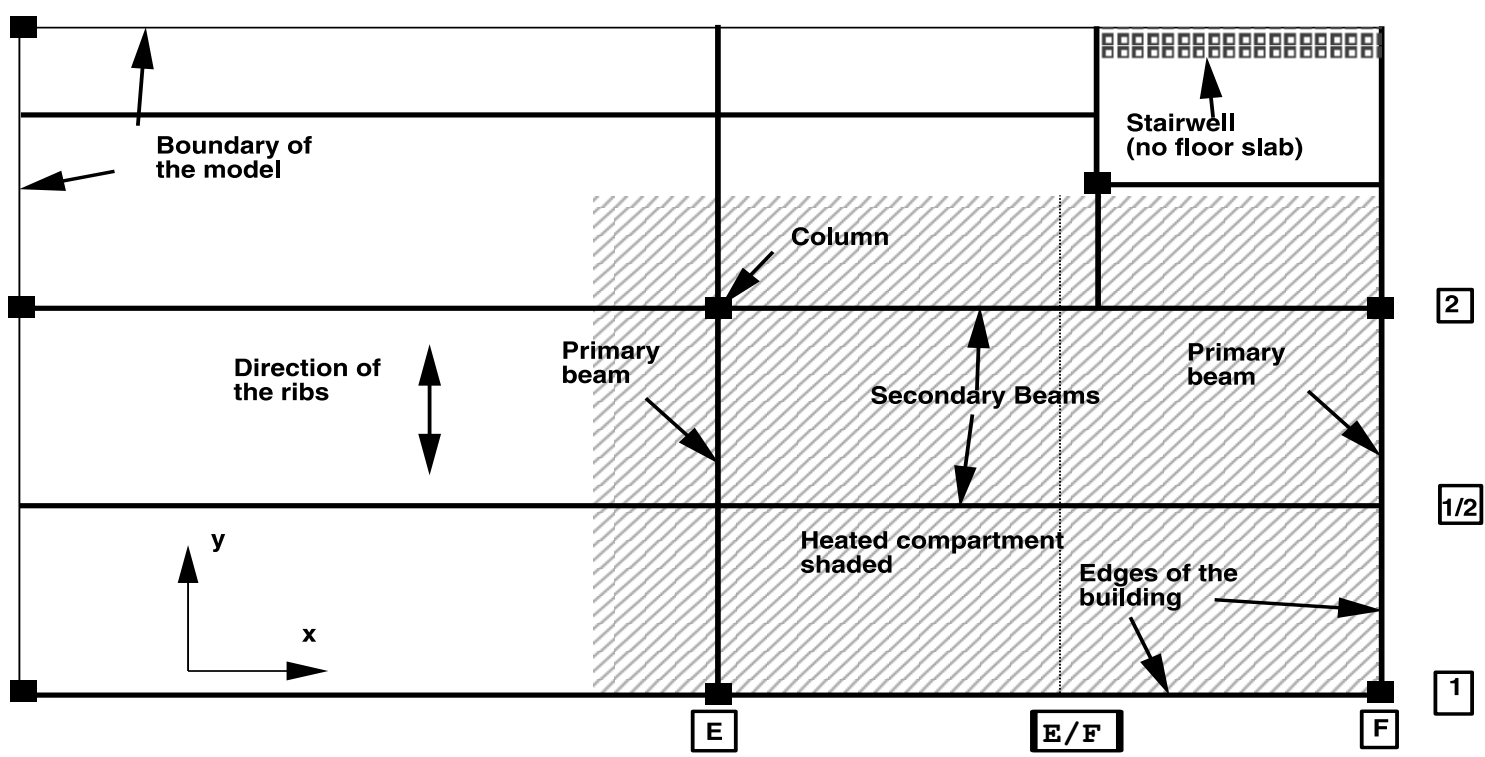

Figure 2: 


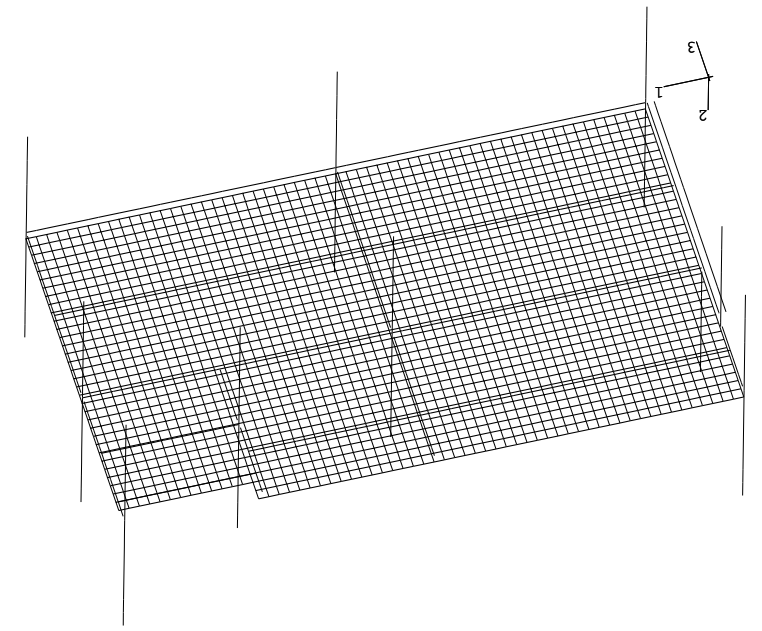

Figure 3: 


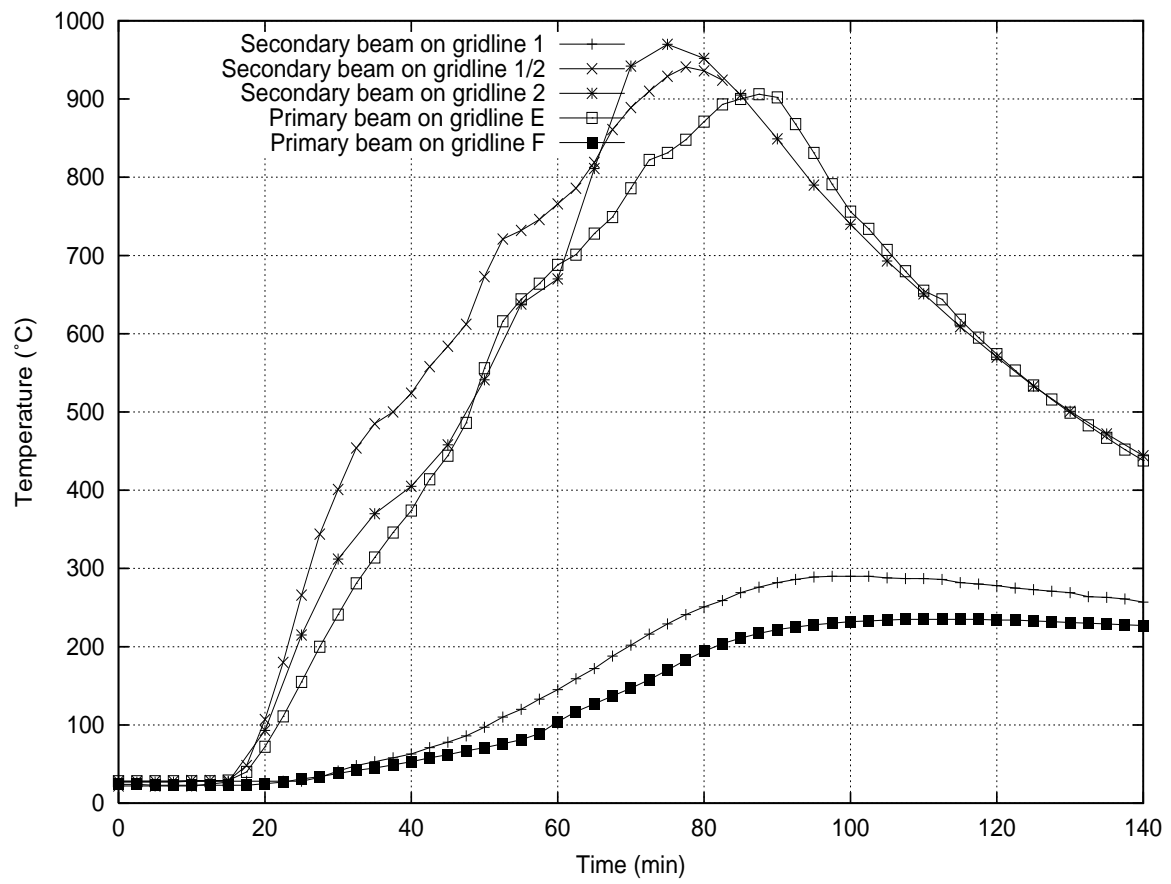

Figure 4: 


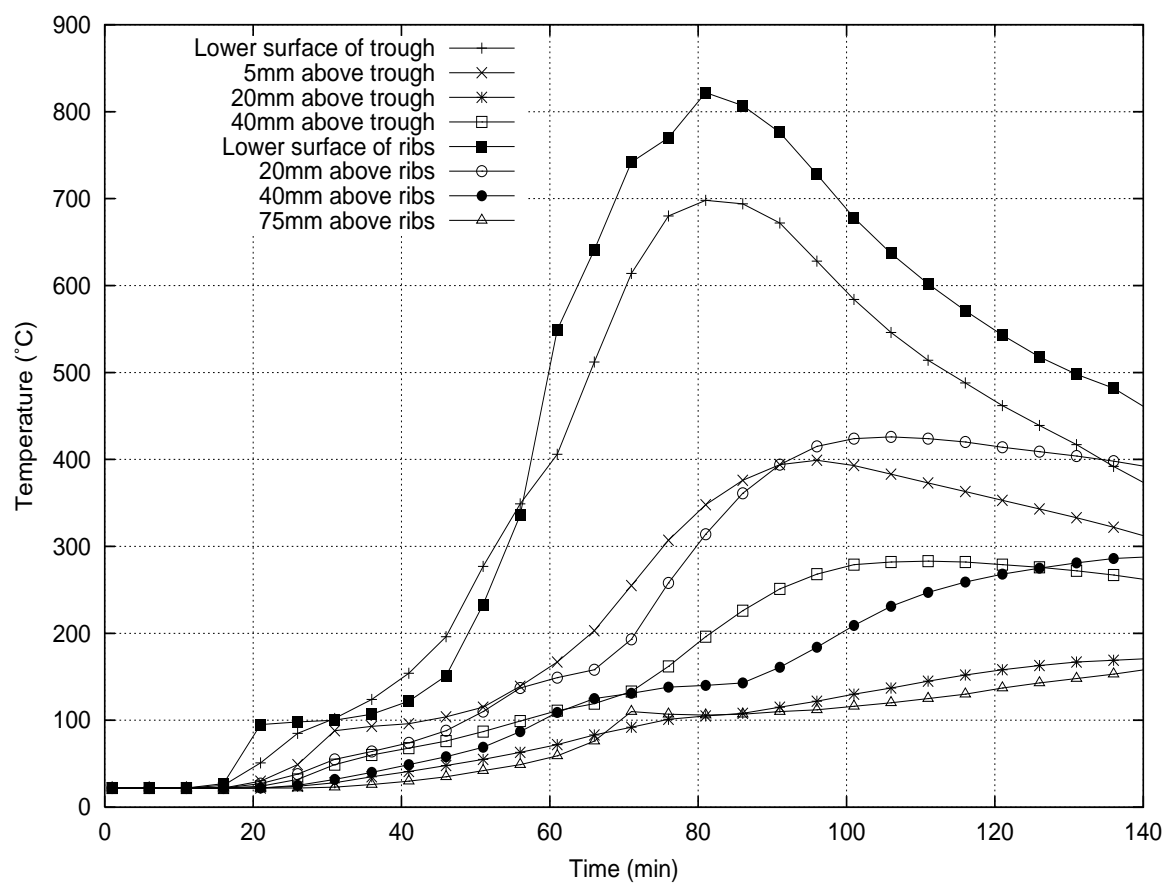

Figure 5: 


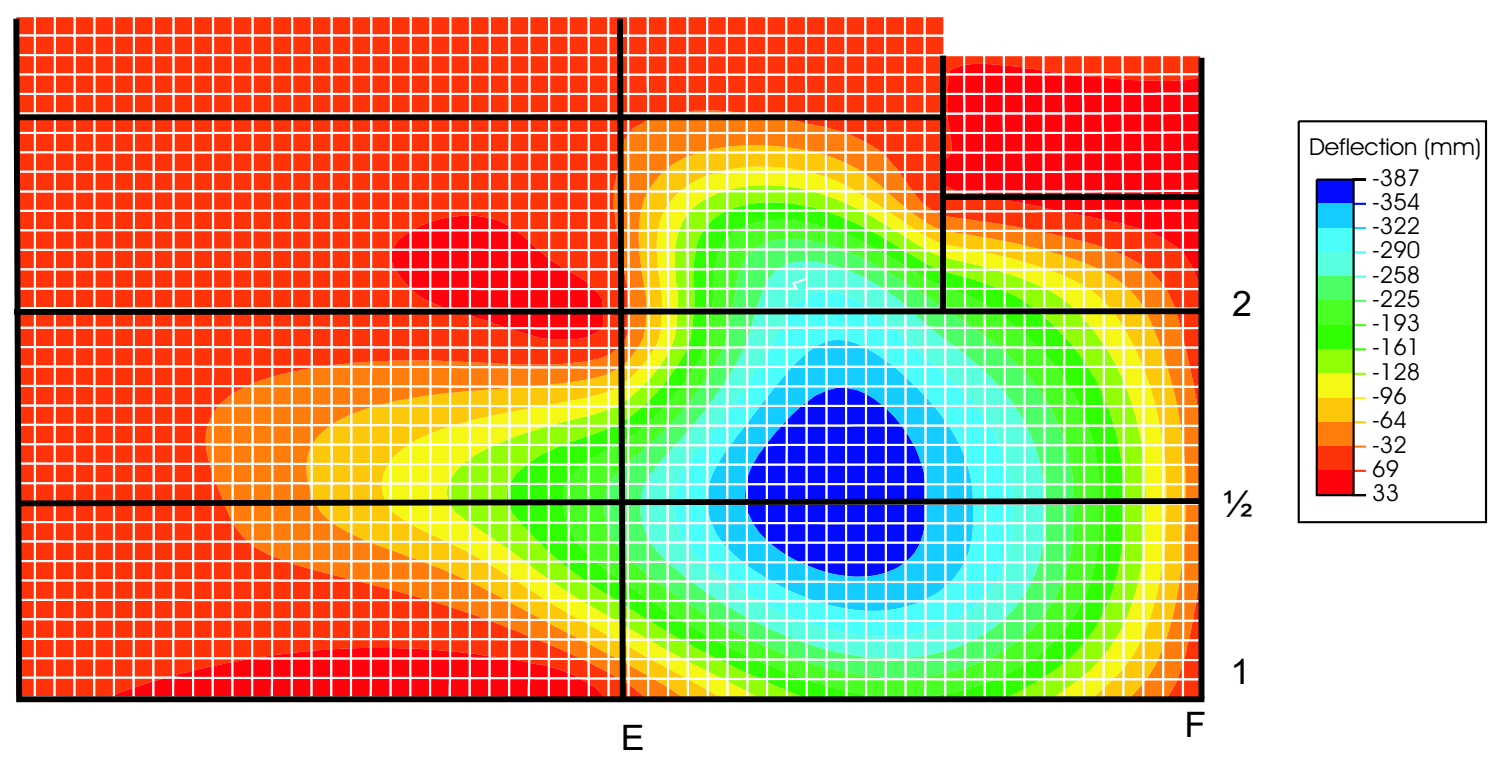

Figure 6: 


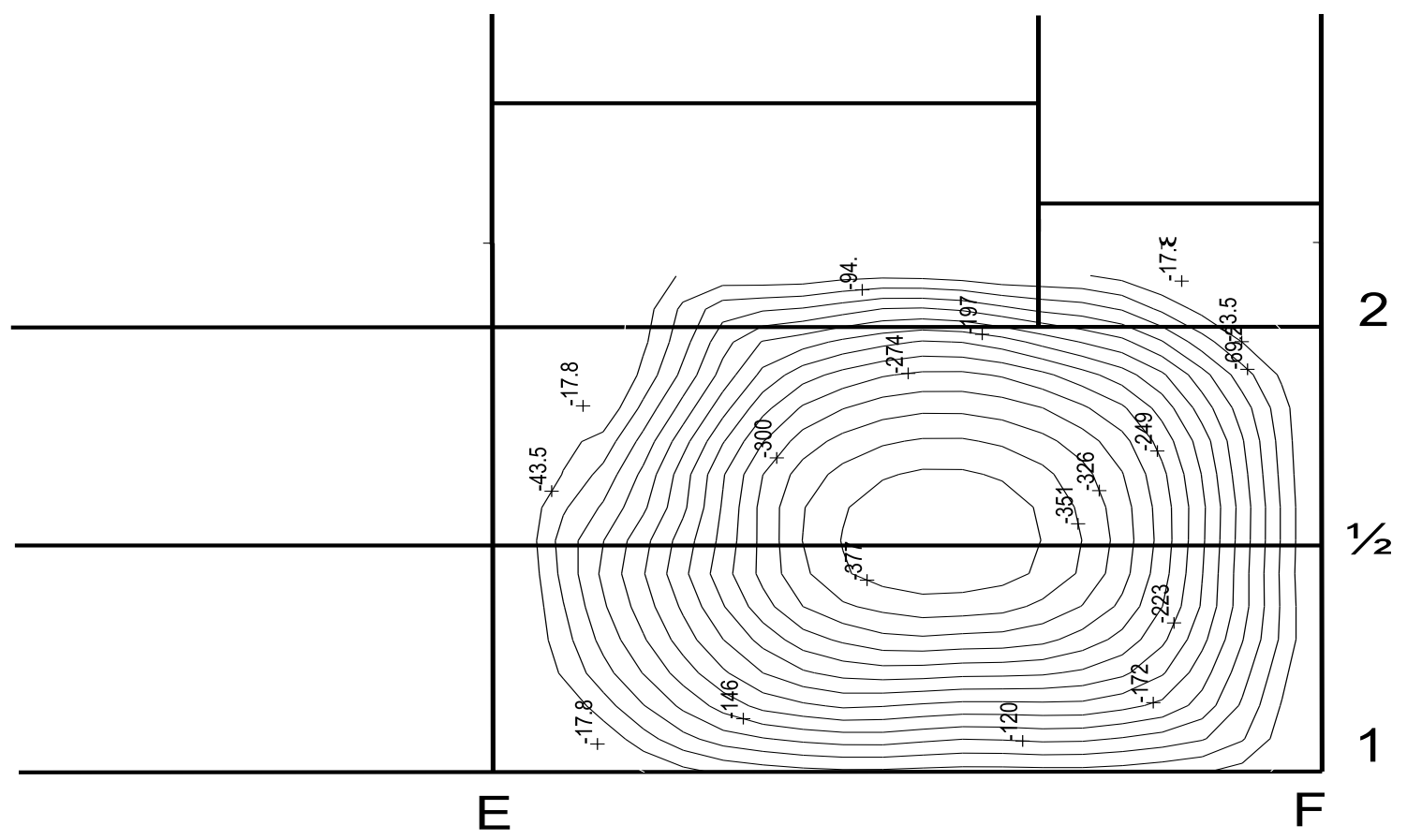

Figure 7: 


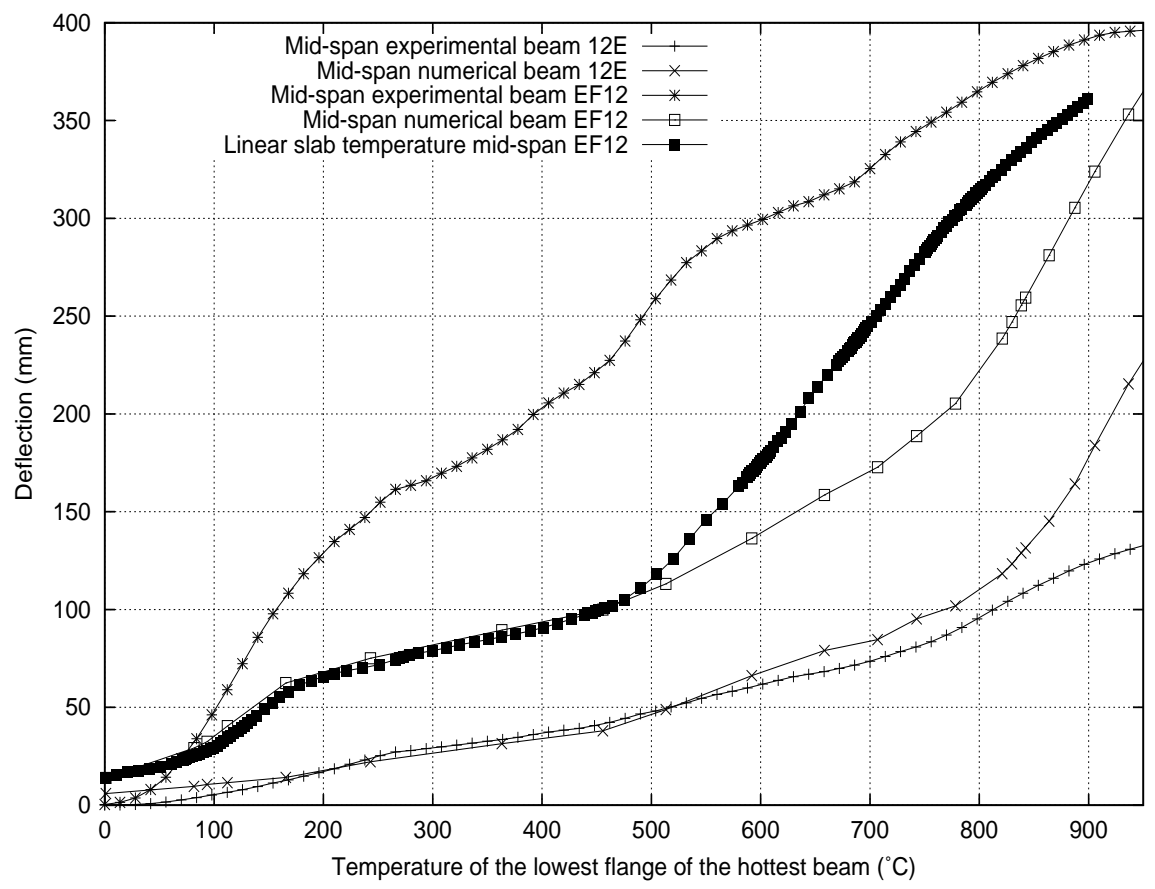

Figure 8: 


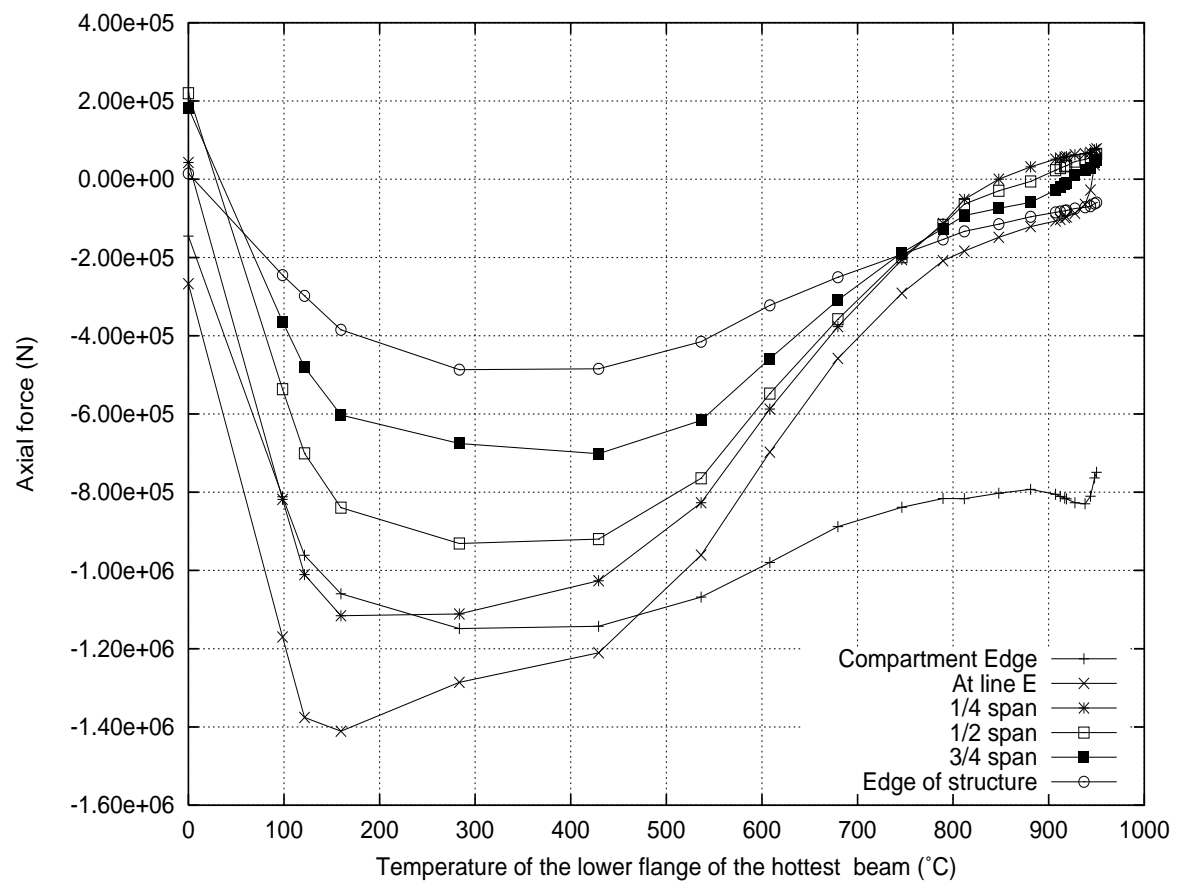

Figure 9: 


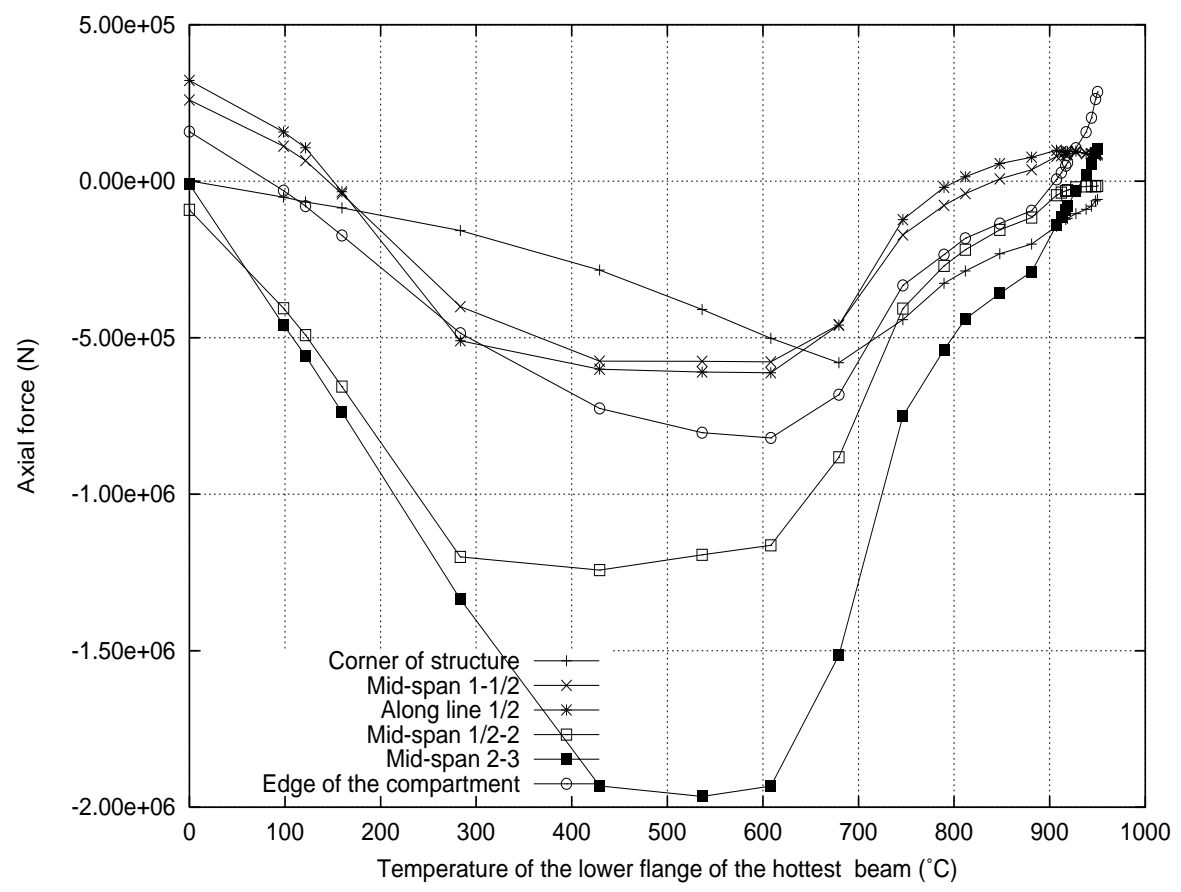

Figure 10: 


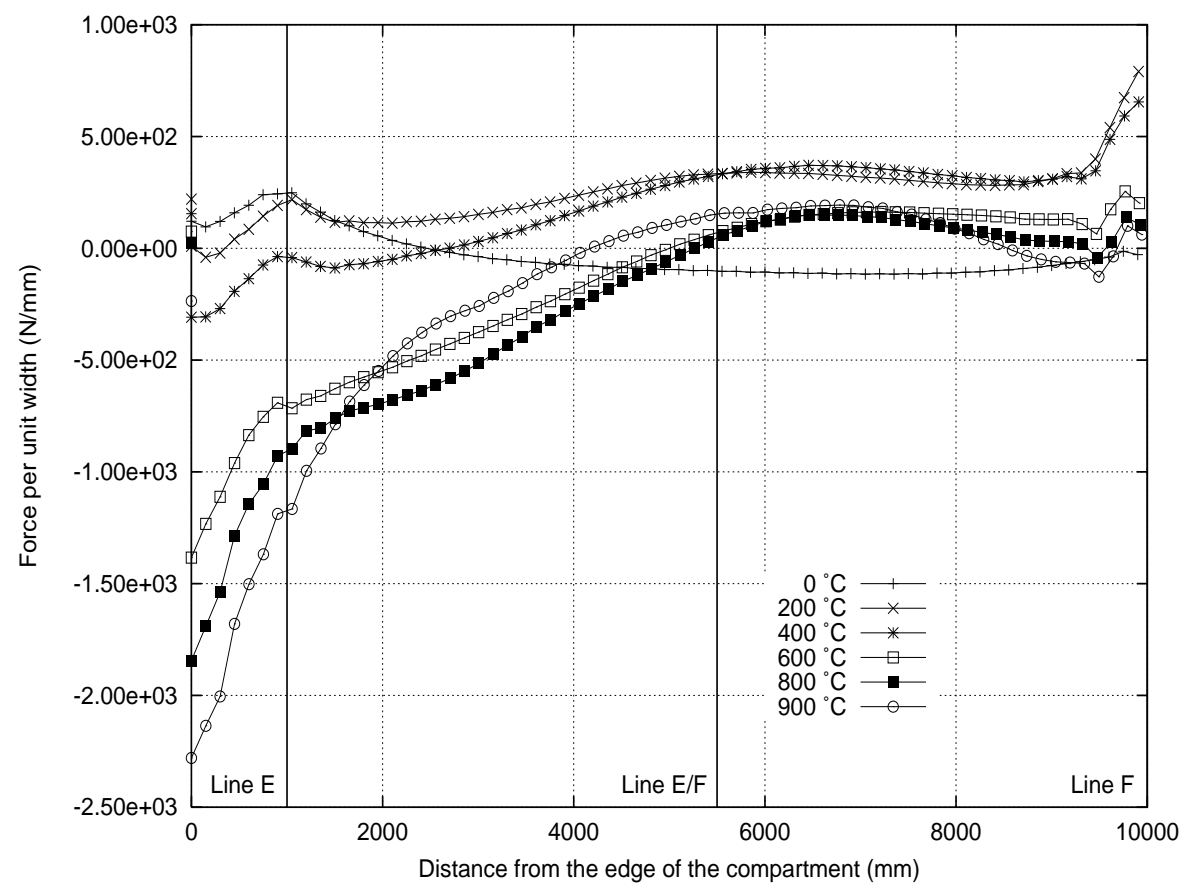

Figure 11: 


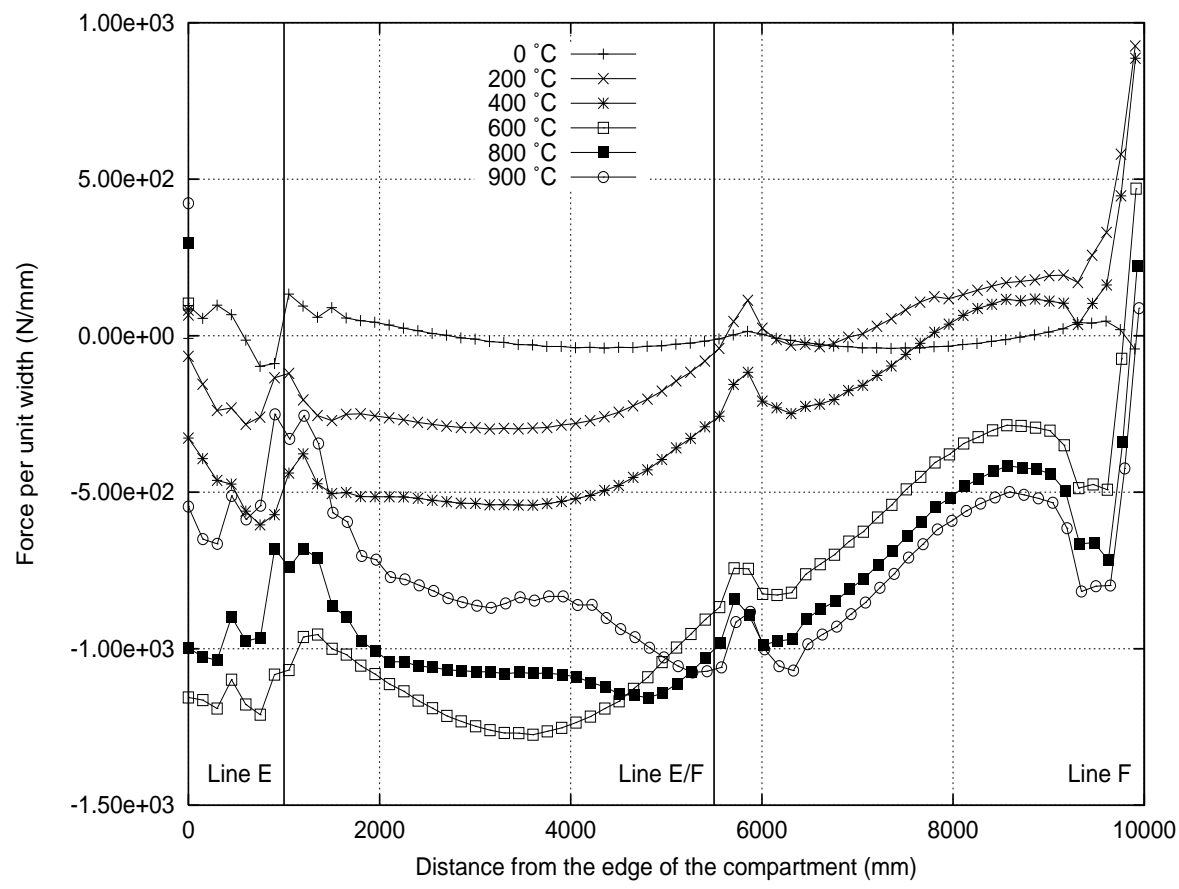

Figure 12: 


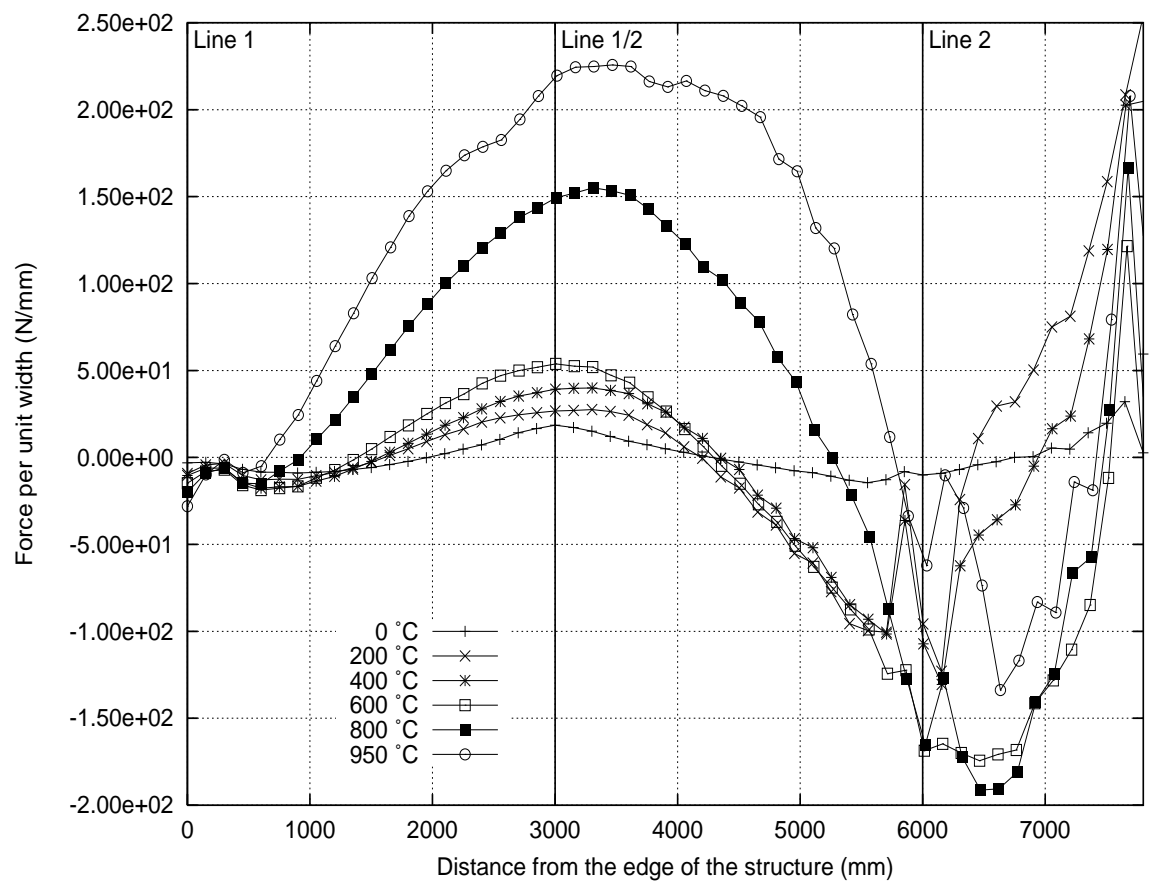

Figure 13: 


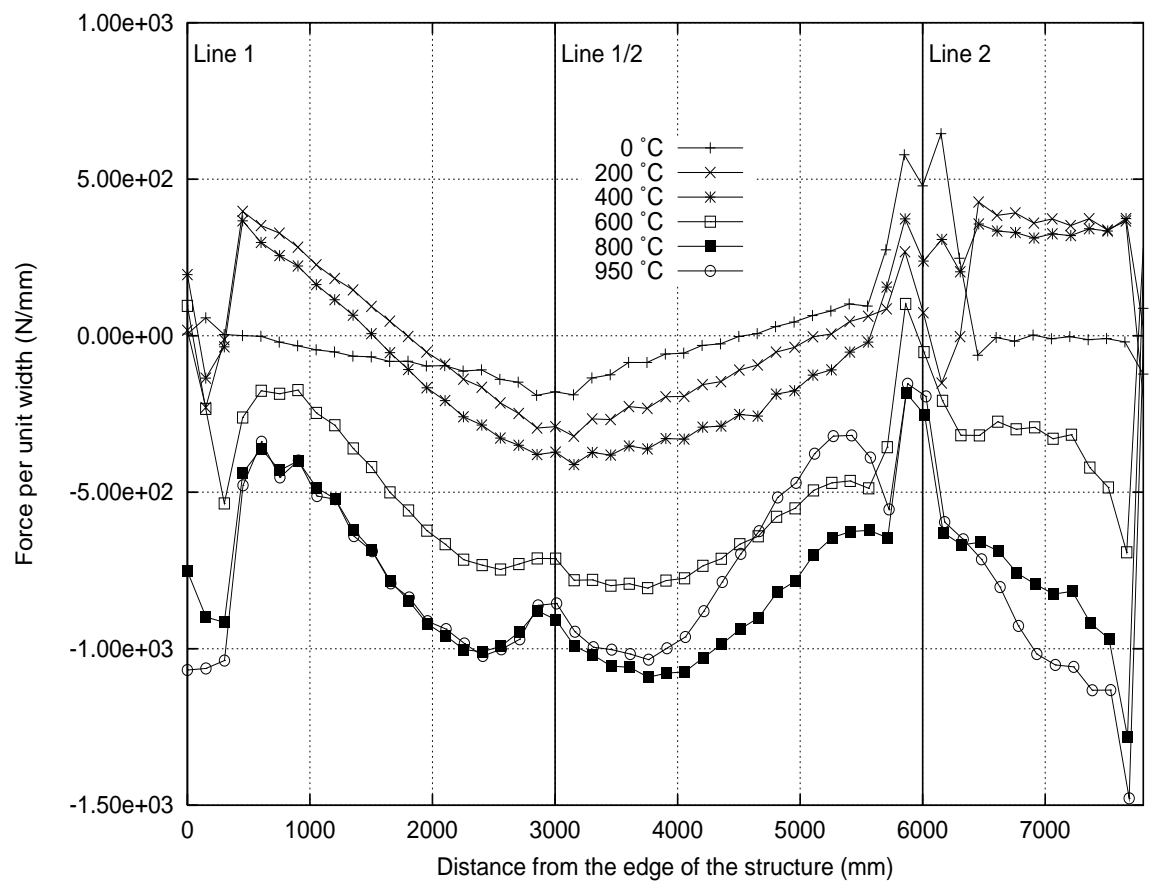

Figure 14: 


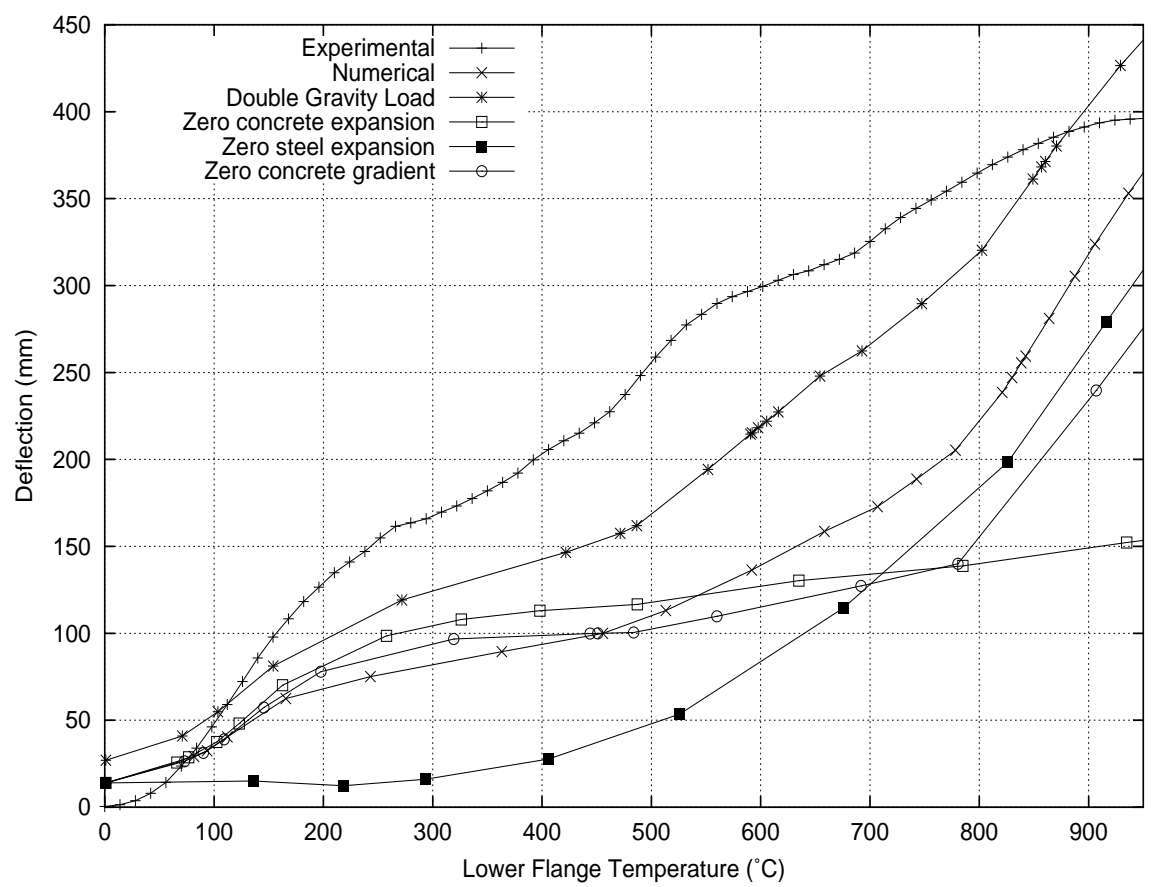

Figure 15: 


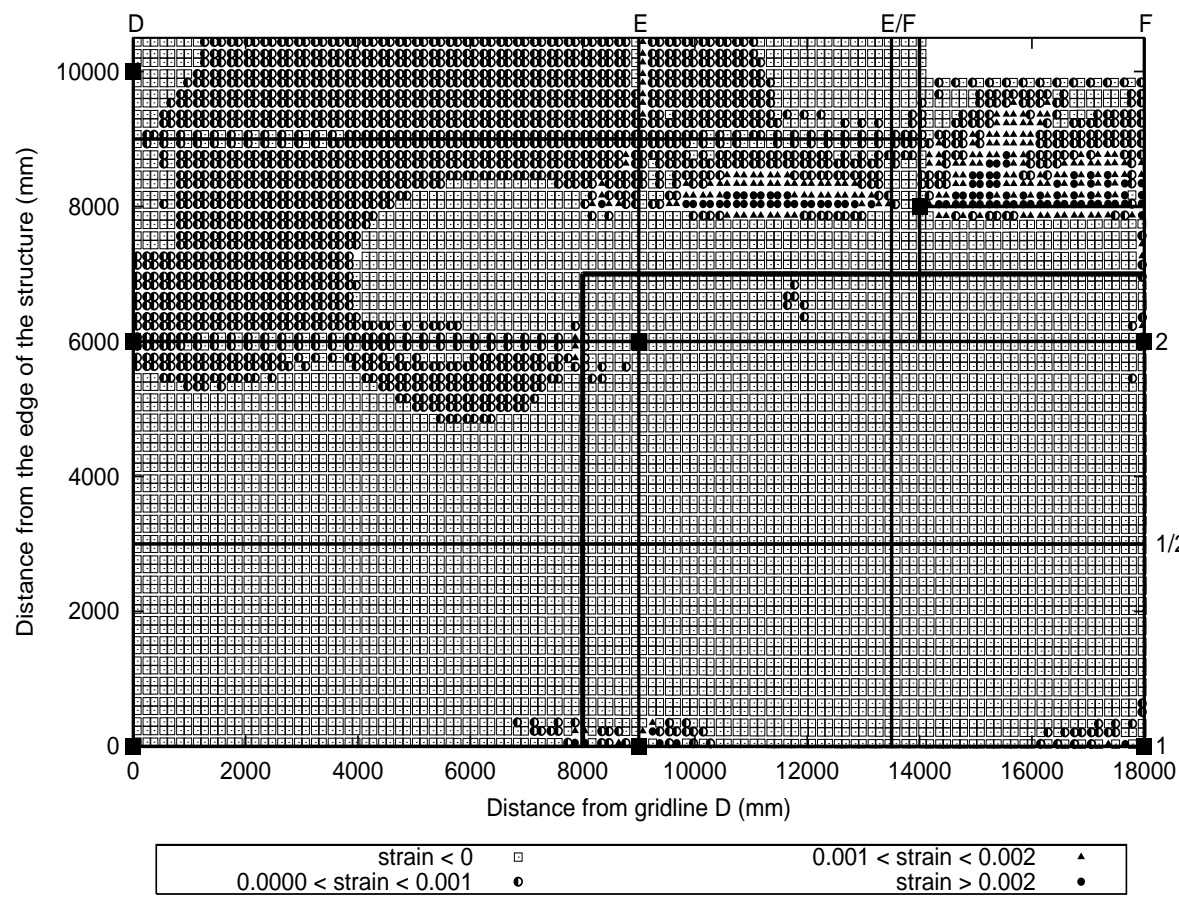

Figure 16: 


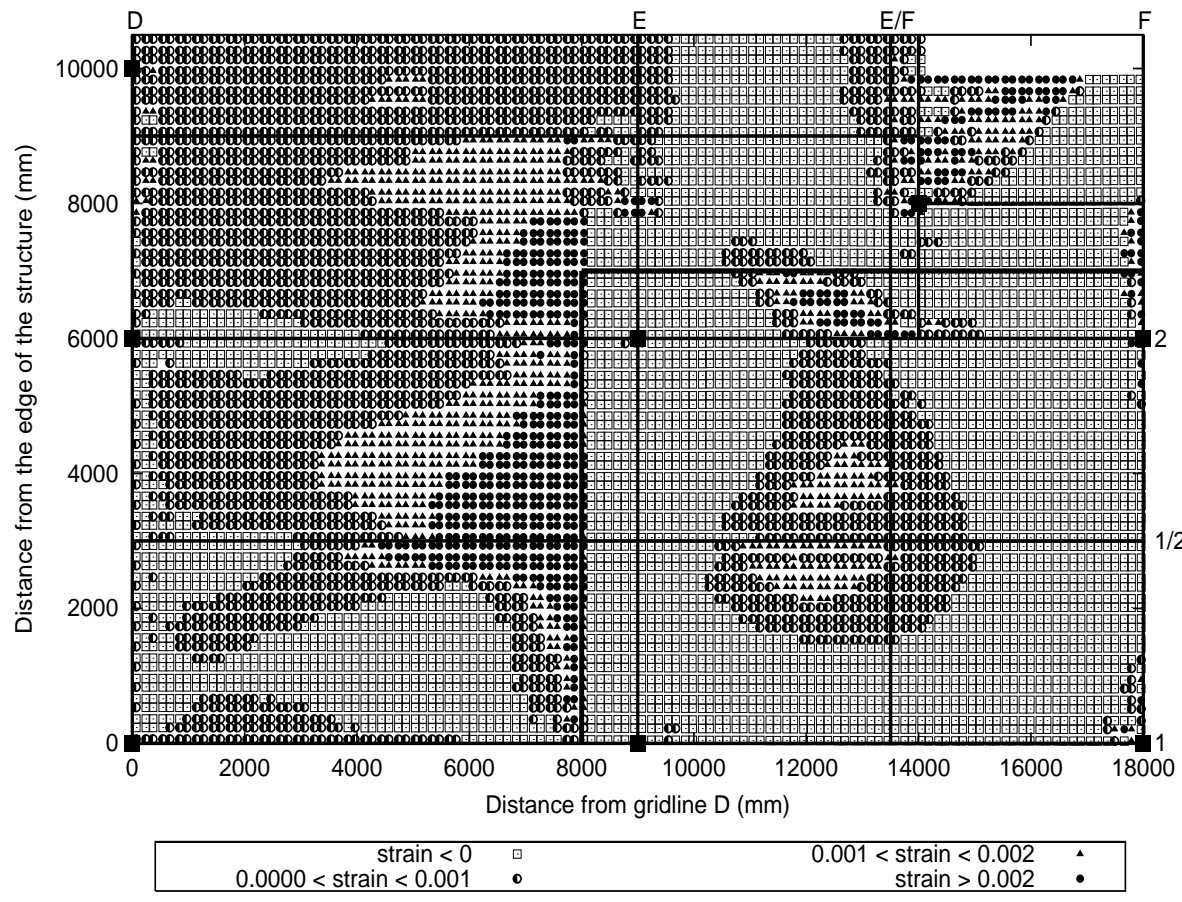

Figure 17: 